\title{
COMPARATIVE STUDY OF LIGHT SOURCES FOR HOUSEHOLD
}

\author{
Andrzej PAWLAK \\ Central Institute for Labour Protection - National Research Institute \\ Małgorzata ZALESIŃSKA \\ Poznan University of Technology
}

\begin{abstract}
:
The article describes test results that provided the ground to define and evaluate basic photometric, colorimetric and electric parameters of selected, widely available light sources, which are equivalent to a traditional incandescent 60 Watt light bulb. Overall, one halogen light bulb, three compact fluorescent lamps and eleven LED light sources were tested. In general, it was concluded that in most cases (branded products, in particular) the measured and calculated parameters differ from the values declared by manufacturers only to a small degree. LED sources prove to be the most beneficial substitute for traditional light bulbs, considering both their operational parameters and their price, which is comparable with the price of compact fluorescent lamps or, in some instances, even lower.
\end{abstract}

Key words: bulb's replacement, photometric, colorimetric and electric parameters light sources, light-emitting diode (LED), light sources for household

\section{INTRODUCTION}

Currently, the market offers a number of alternatives to incandescent light bulbs. One of them are energy-saving compact fluorescent lamps, which, in comparison with traditional light bulbs, consume up to $80 \%$ of energy less and their lifetime is 6-12 times longer. The second group is comprised of the new-generation halogen light bulbs that help reduce the energy consumption by around $20 \%$ and offer twice the lifetime of an incandescent lamp. The third and last group are the light sources based on solid-state physics, i.e. light-emitting diodes (LED), which guarantee the most substantial reductions in consumption of energy (over $80 \%$ ) and at the same time achieve the longest lifetime, 10 to 30 times longer than traditional light bulbs. For the most part, consumers tend to choose substitutes for incandescent light bulbs on the ground of the lighting technology used, price and/or parameters declared by the manufacturer, such as rated power, equivalent incandescent lamp power and color temperature.

The purpose of the conducted tests was to define and evaluate basic photometric, colorimetric, and electric parameters of selected light sources. The results of these tests were used as the foundation for the verification of manufacturers' declarations concerning the tested parameters and the conformity of such declarations with applicable regulations $[1,2,3]$ and standards $[7,8,9,10]$. None of the tests focused on the verification of lifetime, maintenance of the luminous flux during operation, nor the number of switching cycles.

\section{SELECTION CRITERIA}

Tests were conducted on a selection of non-directional, widely available light sources that are declared by their manufacturers as replacements for traditional 60-Watt incandescent light bulbs.

The light sources were selected for testing according to the following pattern:

- determination of groups of light sources that are regarded as alternatives to traditional light bulbs, i.e. compact fluorescent lamps, halogen light bulbs, and LED light sources,

- classification of light sources by their construction:

- new-generation halogen light bulbs fitted in bulbs typical for traditional lamps (Fig. 1),

- compact fluorescent lamps with uncovered tubes and with an additional bulb covering the tubes (Fig. 2),

- LED light sources with the luminous flux angle of > $120^{\circ}$ (Fig. 3),

- warm color temperature,

- light sources from various suppliers, both branded (e.g. PHILIPS, PILA, OSRAM, GE) and "nonames" (imported from Southeast Asia),

- good market availability,

- low or affordable price,

- E27 thread base,

- compatibility with the mains voltage.

All in all, 16 light sources were tested, including one incandescent lamp. 


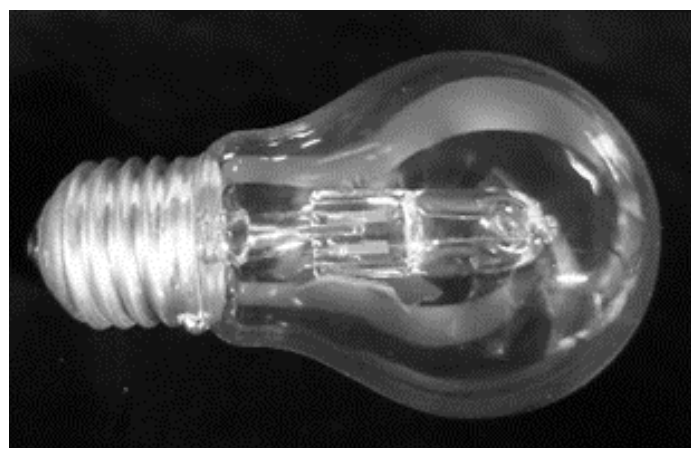

Fig. 1 View of the tested halogen light bulb

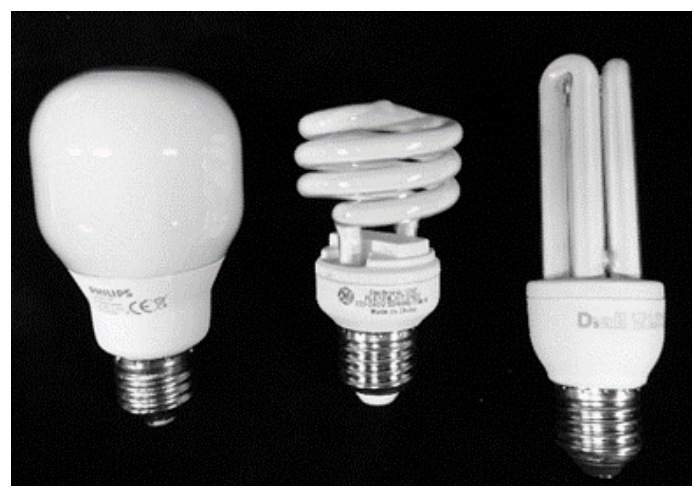

Fig. 2 View of the tested compact fluorescent lamps

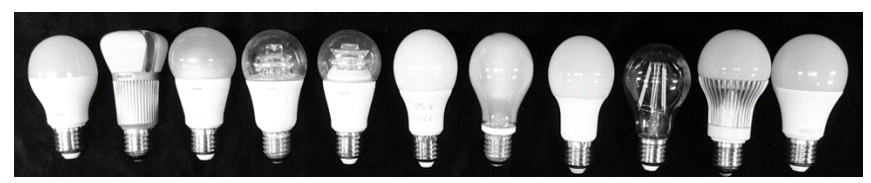

Fig. 3 View of the tested LED light sources

\section{CHARACTERISTICS AND REQUIREMENTS OF OPERATIONAL PARAMETERS OF TESTED LIGHT SOURCES}

The basic operational parameters of light sources that are regarded equivalent to incandescent lamps include: lamp power, luminous flux, lifetime, color temperature, color rendering index (CRI), warm-up time, equivalent incandescent lamp power, and energy efficiency index (EEI). These parameters are specified by manufacturers and printed on the product packaging. Obligation to provide such information results from the provisions specified in the regulation [1].

Descriptions and requirements concerning the basic operational parameters of light sources are presented below.

1. Lamp power $W$ defines the amount of power that is consumed by the given light source from the mains. For domestic light sources, this value is usually measured at lamp-holder terminals. Standards $[7,8,9,10]$ define the maximum power that is allowed for the tested light sources in relation to manufacturers' declarations. The acceptable difference in lamp power depends on the type of the light source. The maximum permissible values for commonly used light sources are compiled in Table 1.

2. Rated luminous flux Im is the total quantity of the light emitted by the given light source, as declared by the manufacturer, provided that operating conditions are optimal. The minimum acceptable values of the luminous flux for the respective light sources are specified in applicable standards $[7,8,9,10]$. The minimum luminous flux values for the tested light sources are compared in Table 1.

3. Equivalent incandescent lamp power $\mathbf{W}$ is an estimated value that shows how energy-efficient the particular light source is. The equivalent incandescent lamp power (rounded off to $1 \mathrm{Watt}$ ) is calculated on the basis of the measured value of the luminous flux of its equivalent. The manufacturers' declarations regarding this parameter were verified in accordance with the regulation [1]. Table 1 shows the required luminous flux value of sources that are alternative to traditional light bulbs.

4. Energy efficiency $\mathrm{Im} / \mathrm{W}$ is used to measure the efficiency of light sources. It is the ratio of the emitted luminous flux to the amount of power consumed (with allowance for power losses in the starter and the ballast, which are necessary for providing optimal operating conditions for the lamp). The value of this parameter shows power consumption. The higher it is, the more energy-efficient is the light source. The luminous efficacy of a light source is reflected in the energy efficiency class. According to [8], the luminous efficacy of LED light sources should not be lower than $80 \%$ of the rated luminous efficacy declared by the manufacturer.

5. Energy efficiency class the efficiency of a device and is printed on the energy label as categories from $\mathrm{A}++$ (most efficient) to $E$ (least efficient). The energy efficiency class is determined on the ground of the measured value of the energy efficiency index, abbreviated to EEI (formula 1), which for light sources is defined as the ratio of the rated power lamp $\mathrm{P}_{\text {cor }}$, corrected with allowance for losses in the electronic control equipment, to the reference power $P_{\text {ref, }}$ calculated for non-directional light sources on the basis of the total value of the operational luminous flux $\Phi_{\text {use }}$ use (formula 2) [3]. The value of the EEI index should be provided to two decimal places.

$$
E E I=\frac{P_{\text {cor }}}{P_{\text {ref }}}
$$

Acceptable differences in power and luminous flux with reference to the values declared by manufacturers $[1]$ and $[7,8,9,10]$

\begin{tabular}{cccc}
\hline Parameter & $\begin{array}{c}\text { Incandescent } \\
\text { lamp }\end{array}$ & $\begin{array}{c}\text { Tungsten halogen } \\
\text { lamp }\end{array}$ & $\begin{array}{c}\text { Compact } \\
\text { fluorescent lamp } \\
\text { (integrated) }\end{array}$ \\
\hline $\begin{array}{c}\text { Minimum value of the luminous flux } \\
\text { in \% of the declared value } \\
\begin{array}{c}\text { The maximum value of the power } \\
\text { in \% of the declared value }\end{array}\end{array}$ & 95 & 90 & 90 \\
\hline $\begin{array}{c}\text { Luminous flux for the declared equivalent incandescent } \\
\text { lamp power for } 60 \mathrm{~W}\end{array}$ & 104 & 108 & 115 \\
\hline
\end{tabular}




$$
P_{\text {ref }}=0.88 \sqrt{\Phi_{\text {use }}}+0.49 \Phi_{\text {use }} \text { for } \Phi_{\text {use }}<1300 \mathrm{~lm}
$$

and

$$
P_{\text {ref }}=0.7341 \Phi_{\text {use }} \text { for } \Phi_{\text {use }}<1300 \mathrm{~lm}
$$

Table 2 lists energy efficiency classes of non-directional light sources for respective values of the energy efficiency index.

Table 2

Energy efficiency class non-directional lamps

\begin{tabular}{cc}
\hline Energy efficiency class & $\begin{array}{c}\text { Energy efficiency index (EEI) } \\
\text { for non-directional lamps }\end{array}$ \\
\hline$A++$ (most efficient) & EEI $\leq 0.11$ \\
$A+$ & $0.11<\mathrm{EEI} \leq 0.17$ \\
A & $0.17<\mathrm{EEI} \leq 0.24$ \\
$\mathrm{~B}$ & $0.24<\mathrm{EEI} \leq 0.60$ \\
C & $0.60<\mathrm{EEI} \leq 0.80$ \\
$D$ & $0.80<\mathrm{EEI} \leq 0.95$ \\
E (least efficient) & $\mathrm{EEI}>0.95$ \\
\hline
\end{tabular}

The energy efficiency class was verified in accordance with the Commission Delegated Regulation (EU) [3] supplementing Directive 2010/30/UE of the European Parliament and the Council on labeling lamps and lighting fixtures with information on the consumption of energy. It is assumed that the energy efficiency index of the tested light source corresponds with the declared energy efficiency class if the designated EEI value does not exceed the declared value by more than $10 \%$. The sample energy label for an LED light source is depicted in Fig. 4.

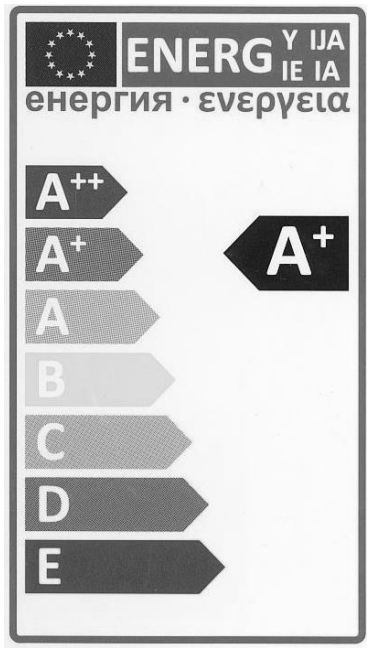

$10 \mathrm{kWh} / 100 \mathrm{~h}$

\section{Fig. 4 The sample energy label for an LED light source}

Life - is measured in hours. It denotes the time that passes before the light source burns out or the emitted luminous flux drops under the allowable limit. Such value is known as the operational lifetime. There is also the declared lifetime, which is provided by the manufacturer. It is usually higher than the operational lifetime. In case of LED light sources, this parameter is defined by the maintenance of the luminous flux to the foreseen value and the number of burnt out chips in LED lamps (both expressed as a percentage) at the moment when the drop in the luminous flux takes place.

Colour rendering index (CRI) is a dimensionless value. It is used to measure the ability of a light source to reveal the actual colors of an illuminated object in comparison with the same object illuminated by a reference light source in specific conditions. The maximum value for this index is 100 , and it is attributed to sunlight and incandescent lamps. The closer to the value of 100 the index is, the better are the color rendering abilities of the light source. For the light sources used in domestic applications, the CRI rating should be at least $80[1,2]$.

Colour temperature $[\mathrm{K}]$ is defined as the absolute temperature of a black body which radiates light of identical or similar chromaticity as the given light source. Color temperature of the tested light sources amounted to $2.700 \mathrm{~K} \div$ $3.000 \mathrm{~K}$, thus making the emitted light warm (white warm). According to [4], if the declared color temperature of the light source is $2.700 \mathrm{~K}$, the measured temperature should be between $2.580 \mathrm{~K} \div 2.870 \mathrm{~K}$, and if the declared temperature is $3.000 \mathrm{~K}$, then the measured value should be between $2.870 \mathrm{~K} \div 3.220 \mathrm{~K}$.

Minimum number of switching cycles is calculated on the basis of the rated lifetime and declared by the manufacturer. It denotes the number of switching cycles preceding a failure. This information is of particular importance in case of compact fluorescent lamps. The number of switching cycles should not be lower than the lamp's lifetime (measured in hours) [1]. In case of halogen light bulbs, the number of cycles does not influence their lifetime. For LED sources, this number is within 10.000 to 100.000 . According to the regulation [2], the number of switching cycles should at least amount to the half of the lamp's rated lifetime if it does not exceed 30000 hours, and at least 15.000 if the lifetime is greater than or equal to 30000 hours.

Warm-up time $s$ is the time that is needed for the light source to achieve its rated luminous flux. This information is particularly significant for compact fluorescent lamps. In comparison with LED light sources and halogen light bulbs, standard compact fluorescent lamps take a little more time before they warm up and achieve their rated luminous flux. In practical terms, compact fluorescent lamps need up to 2 seconds to start and up to 40 seconds to achieve $60 \%$ of their rated luminous flux, or even 100 seconds in case of lamps that contain mercury amalgam (lamps with an additional bulb) [1]. For incandescent light bulbs, warm-up time is considerably shorter and should not exceed 1 second. In case of LEDs, the warm-up time is specified for $95 \%$ of the fixed luminous flux and should not exceed 2 seconds [2].

\section{TESTING METHOD}

\section{Measurement of colorimetric parameters}

Colorimetric parameters were measured with the GL SPECTOCS 5.0 Touch spectrometer (GL OPTICS) in the setup presented in Fig. 5. Based on the measurement of the spectral distribution of the light source, the spectrometry software calculated the CRI and the color temperature. The tested light source was positioned in the axis of the spectroradiometric detector and in the distance that enabled the emission of light of the luminous intensity of $500 \mathrm{~lx}$ [6]. 


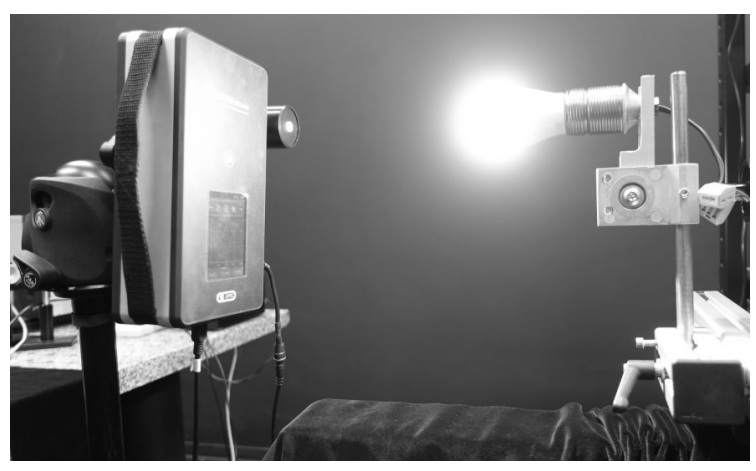

Fig. 5 View of the measuring set for the spectral distribution of a light source

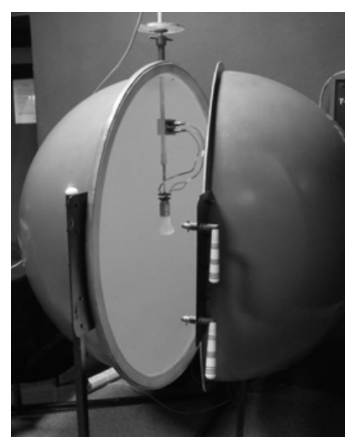

Fig. 6 View of the integrating sphere

Measurement of photometric and electric parameters

The luminous flux was measured in an integrating sphere (Fig. 6) by comparison with a collective model of the luminous flux, using the siliceous cell corrected to $\mathrm{V}(\mathrm{I})$ and the LMT PHOTOMETER B510 digital photoelectric current meter. LED lamps at the measuring station were powered by the KIKUSUI PCR500M laboratory power supply unit. At the start-up, changes in the luminous flux were observed $F=f(t)$. Electric parameters of respective LED light sources were measured with the aid of the LEM Power Analyzer Norma 4000 power meter. The luminous flux and electric parameters were measured at $230 \mathrm{~V}$ and $f=50 \mathrm{~Hz}$. The measurement results were used to compute the warm-up time of respective lamps and calculate their luminous efficacy, equivalent incandescent lamp power rating, and energy efficiency indices. Results of measurements and calculations are presented in Tables 3, 4 and 5.

\section{RESULTS}

Table 3 compiles the types of tested light sources along with their manufacturers, unique codes and parameters declared by manufacturer that were not tested - life and number of switching cycles. Furthermore it compares warm -up time measured and required in regulations [1, 2].

Table 4 compares the measured colour rendering index, colour temperature, luminous flux and energy efficiency with the values declared by manufacturers. Furthermore, the based on standard $[4,5,6,7]$ minimum allowable value of the luminous flux for respective light source types was calculated.

Table 5 compares the measured lamp power and equivalent incandescent lamp power with the values declared by manufacturers and the maximum permissible discrepancy between the actual power of a light source and the manufacturer-declared power rating $[7,8,9,10]$.

Moreover, for each light source, the energy efficiency index was calculated and used to define the energy efficiency class (according to [3]), which was then compared to the class declared on the energy label.

Table 3

Tested light sources along with their manufacturers, unique codes, and operational parameters declared by manufacturer

\begin{tabular}{|c|c|c|c|c|c|c|c|c|}
\hline \multirow[b]{2}{*}{ No. } & \multirow{2}{*}{$\begin{array}{c}\text { Code } \\
\text { of light } \\
\text { sources }\end{array}$} & \multirow[b]{2}{*}{ Type of light sources } & \multirow{2}{*}{$\begin{array}{l}\text { Manufacturer/ } \\
\text { importer }\end{array}$} & \multirow{2}{*}{$\begin{array}{l}\text { Power } \\
{[W]}\end{array}$} & \multirow{2}{*}{$\begin{array}{l}\text { Life } \\
\text { [h] }\end{array}$} & \multirow{2}{*}{$\begin{array}{l}\text { Number of } \\
\text { switching } \\
\text { cycles }\end{array}$} & \multicolumn{2}{|c|}{ Warm-up time [s] } \\
\hline & & & & & & & measurement & directive \\
\hline \multicolumn{9}{|c|}{ INCANDESCENT LAMP } \\
\hline 1. & $\mathrm{Z1}$ & Incandescent lamp & for TESCO & 60 & $1000 \mathrm{~h}$ & no data & $<1 \mathrm{~s}$ & 1 \\
\hline \multicolumn{9}{|c|}{ TUNGSTEN HALOGEN LAMP } \\
\hline 2. & $\mathrm{H} 1$ & $\begin{array}{l}\text { CLASSIC ECO SUPER- } \\
\text { STAR }\end{array}$ & OSRAM & 46 & $2000 \mathrm{~h}$ & no data & $<1 s$ & 1 \\
\hline \multicolumn{9}{|c|}{ COMPACT FLUORESCENT LAMP } \\
\hline 3. & $\mathrm{C} 1$ & SOFTONE & PHILIPS & 12 & 8 years & no data & 35 & 100 \\
\hline 4. & $\mathrm{C} 2$ & DECOR & GE & 12 & 8 years & no data & 33 & 40 \\
\hline 5. & C3 & DIALL & $\begin{array}{l}\text { DIALL, for Cas- } \\
\text { torama }\end{array}$ & 15 & $10000 \mathrm{~h}$ & 30000 & 36 & 40 \\
\hline \multicolumn{9}{|c|}{ LED LAMPS } \\
\hline 6. & L1 & PHILIPS & PHILIPS & 9.5 & $15000 \mathrm{~h}$ & 50000 & $<2 s$ & 2 \\
\hline 7. & L2 & MASTER LEDbulb MV & PHILIPS & 12 & $25000 \mathrm{~h}$ & 20000 & $<2 s$ & 2 \\
\hline 8. & L3 & $\begin{array}{l}\text { PARATHOM CLASSIC } \\
\text { matt }\end{array}$ & OSRAM & 10 & $25000 \mathrm{~h}$ & 100000 & $<2 s$ & 2 \\
\hline 9. & L4 & $\begin{array}{l}\text { PARATHOM CLASSIC } \\
\text { clear }\end{array}$ & OSRAM & 10 & $20000 \mathrm{~h}$ & 100000 & $<2 s$ & 2 \\
\hline 10. & L5 & STAR CLASSIC & OSRAM & 10 & $15000 \mathrm{~h}$ & 100000 & $<2 s$ & 2 \\
\hline 11. & L6 & PILA LED & PILA & 9.5 & $15000 \mathrm{~h}$ & 15000 & $<2 s$ & 2 \\
\hline 12. & L7 & PILA LED & PILA & 7 & $10000 \mathrm{~h}$ & 20000 & $<2 s$ & 2 \\
\hline 13. & L8 & MODOMO & MODOMO & 10 & $20000 \mathrm{~h}$ & 12500 & $<2 s$ & 2 \\
\hline 14. & L9 & DECO LEDbulb & PHILIPS & 7.5 & $15000 \mathrm{~h}$ & 20000 & $<2 s$ & 2 \\
\hline 15. & L10 & AJE-HS2827B & ActiveJet & 10 & $25000 \mathrm{~h}$ & 30000 & $<2 s$ & 2 \\
\hline 16. & $\mathrm{~L} 11$ & HNFE LED & $\begin{array}{l}\text { HNFE for AU- } \\
\text { CHAN }\end{array}$ & 10 & $15000 \mathrm{~h}$ & 10000 & $<2 s$ & 2 \\
\hline
\end{tabular}


Table 4

Operational parameters of tested light sources - declared by manufacturers and measured

\begin{tabular}{|c|c|c|c|c|c|c|c|c|c|}
\hline \multirow{2}{*}{$\begin{array}{l}\text { Code } \\
\text { of light } \\
\text { sources }\end{array}$} & \multicolumn{2}{|c|}{ Colour Rendering Index [-] } & \multicolumn{2}{|c|}{ Colour temperature [K] } & \multicolumn{3}{|c|}{ Luminous flux [Im] } & \multicolumn{2}{|c|}{ Energy efficiency [Im/W] } \\
\hline & declared & $\begin{array}{l}\text { measu- } \\
\text { rement }\end{array}$ & declared & $\begin{array}{l}\text { measu- } \\
\text { rement } \\
\text { INCANDES }\end{array}$ & $\begin{array}{l}\text { declared } \\
\text { NT LAMP }\end{array}$ & $\begin{array}{l}\text { measu- } \\
\text { rement }\end{array}$ & limit value & declared & $\begin{array}{l}\text { measu- } \\
\text { rement }\end{array}$ \\
\hline $\mathrm{Z1}$ & 100 & 99.8 & 2,700 & 2,704 & 710 & 745 & 675 & 12 & 12 \\
\hline \multicolumn{10}{|c|}{ TUNGSTEN HALOGEN LAMP } \\
\hline $\mathrm{H} 1$ & 100 & 98.9 & no data & 2,648 & 700 & 633 & 630 & 15 & 14 \\
\hline \multicolumn{10}{|c|}{ COMPACT FLUORESCENT LAMP } \\
\hline $\mathrm{C} 1$ & no data & 81.4 & ww & 2,701 & 610 & 565 & 549 & 51 & 52 \\
\hline $\mathrm{C} 2$ & no data & 82.9 & 2,700 & 2,760 & 700 & 775 & 630 & 58 & 65 \\
\hline C3 & no data & 81 & 2,700 & 2,679 & 799 & 796 & 719 & 53 & 58 \\
\hline \multicolumn{10}{|c|}{ LED LAMPS } \\
\hline L1 & $>80$ & 81.9 & 2,700 & 2,698 & 806 & 786 & 725 & 85 & 86 \\
\hline L2 & no data & 79.4 & 2,700 & 2,550 & 806 & 783 & 725 & 67 & 66 \\
\hline L3 & 80 & 81.2 & 2,700 & 2,674 & 806 & 787 & 725 & 81 & 83 \\
\hline L4 & 80 & 78.9 & 2,700 & 2,632 & 810 & 872 & 729 & 81 & 89 \\
\hline L5 & 80 & 81.1 & 2,700 & 2,674 & 806 & 808 & 725 & 81 & 84 \\
\hline L6 & no data & 81.1 & 2,700 & 2,744 & 806 & 776 & 725 & 85 & 81 \\
\hline L7 & 80 & 80.7 & 2,700 & 2,963 & 806 & 727 & 725 & 115 & 103 \\
\hline L8 & 80 & 80.4 & white & 2,964 & 806 & 769 & 725 & 81 & 95 \\
\hline L9 & no data & 79.9 & 2,700 & 2,672 & 806 & 792 & 725 & 107 & 107 \\
\hline L10 & no data & 73.1 & 2,700 & 2,938 & 806 & 796 & 725 & 81 & 81 \\
\hline L11 & no data & 82.1 & 3,000 & 3,056 & 806 & 729 & 725 & 81 & 77 \\
\hline
\end{tabular}

Table 5

Power and energy efficiency of tested light sources - declared by manufacturers, measured or calculated

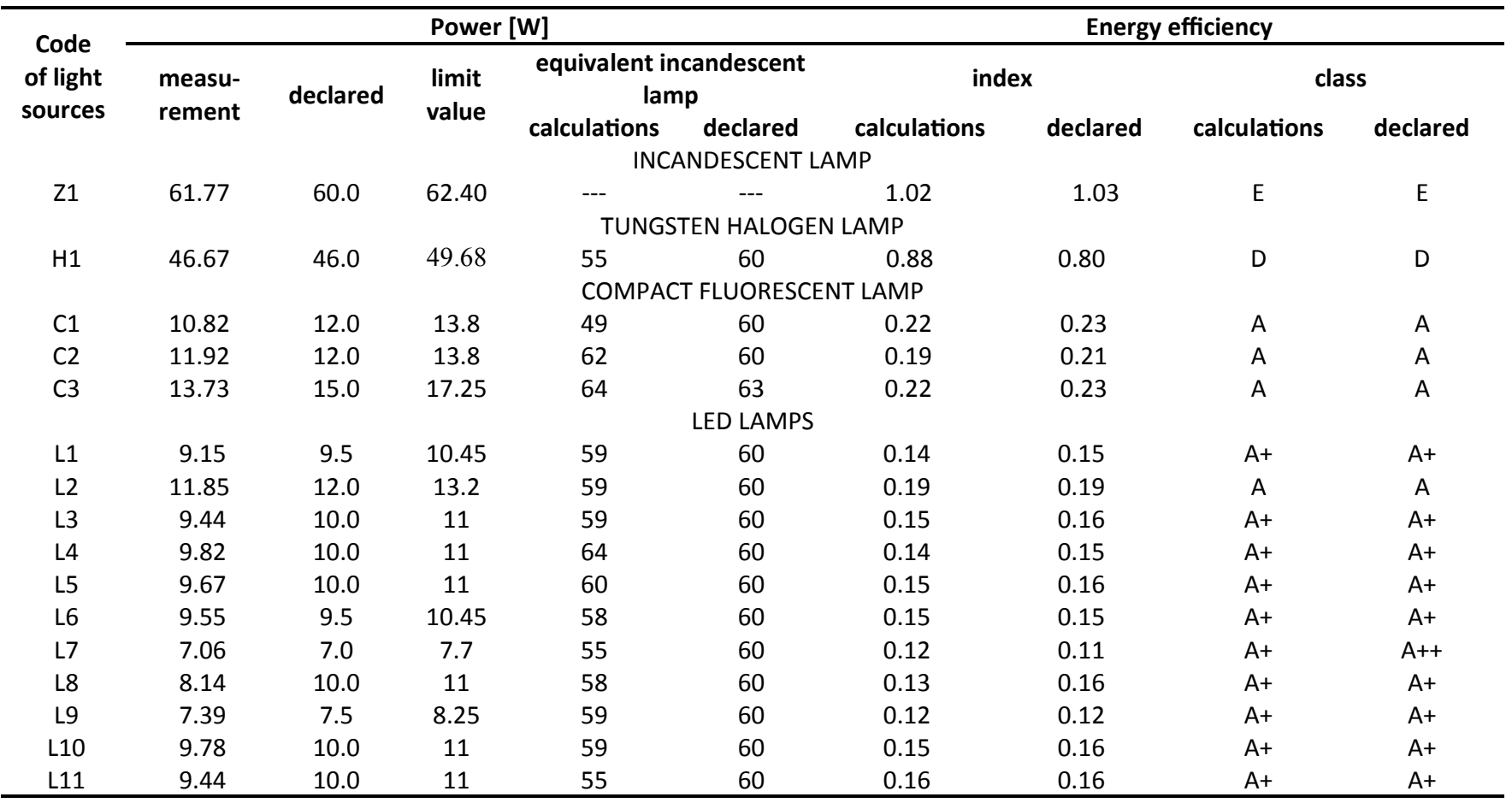

\section{PRESENTATION OF TEST RESULTS}

On the ground of measurements listed in Table 3, it was concluded that:

- concerning the luminous flux, all tested light sources satisfied the criteria for the minimum value of this parameter $[7,8,9,10]$. Still, near-threshold values were confirmed in the halogen light bulb $(9.6 \%)$ and two LEDs (9.5\% and 9.9\%). In case of four light sources, discrepancies between the measured and manufacturer-declared values amounted to $0.2 \%$, $5.0 \%, 7.7 \%$, and $10.7 \%$. The remaining light sources showed values lower than declared by $0.4 \%-9.9 \%$,
- concerning the declared power, all tested light sources met the criterion for the maximum power [ 7 , $8,9,10]$. It needs to be emphasized that all compact fluorescent lamps and nine LED light sources failed to exhibit the power declared by the manufacturer. In two compact fluorescent lamps, the disclosed differences were rather considerable (8.5\% and $9.9 \%)$. In case of two LEDs, this discrepancy amounted to $5.6 \%$ and $18.6 \%$, while other light sources of this type did not exceed $3.6 \%$,

- concerning the luminous efficacy, all tested LED light sources met the criteria for the minimum value of 
this parameter. For five LED light sources, in case of which the luminous efficacy calculated on the ground of measurements is lower than the values declared by the manufacturer, the difference amounts to $0.2 \%$ $-10.7 \%$. In six LEDs, the measured luminous efficacy is higher than declared by $1 \%$ to $17.3 \%$,

- concerning the measured equivalent incandescent lamp power, two compact fluorescent lamps and one LED light source exposed values higher than declared by the manufacturer by $1.6 \%, 3.3 \%$, and $6.7 \%$, respectively. In one light source (LED), this value matched the manufacturer's declaration. For the remaining LEDs, the difference amounted to $1.6 \%$ $8.3 \%$. The third fluorescent lamp showed the discrepancy of $18.3 \%$, and the halogen light bulb differed from the declared value by $8.3 \%$,

- concerning the energy efficiency index (EEI), only one LED light source did not meet the criteria for the admissible difference between the measured and manufacturer-declared values of this index [3]. For one halogen light bulb and one LED light source, the measured EEI index touched the threshold of permissibility, amounting to $9.9 \%$ and $9.7 \%$, respectively. In case of one LED light source, the measured energy efficiency class proved lower than declared by the manufacturer $(A+$ instead of $A++)$. Still, the criteria were satisfied [3],

- concerning the warm-up time, all tested light sources met the criteria for the minimum value of this parameter [1],

- concerning the measured color rendering index, seven LED light sources satisfied the criteria specified in $[1,2]$. For one LED light source, the measured index approached the threshold with the result of 79.9. Another one arrived just under the limit (78.9), and the third one showed the index of 73.1. The index for the LED light source, the manufacturer of which did not declare the CRI, was calculated at 79.4,

- concerning the measured color temperature, two compact fluorescent lamps and seven LED light sources satisfied the criteria specified in [8]. One fluorescent lamp labeled by the manufacturer as warm white and one LED light source labeled as white exhibited warm color temperatures ( 2,700K and $3,000 \mathrm{~K}$, respectively). The measured values proved slightly overstated in two LED light sources (by $82 \mathrm{~K}$ and $93 \mathrm{~K}$ ) and understated in only one (by $30 \mathrm{~K}$ ). Nevertheless, their color temperature remains warm in accordance with the standard [5].

\section{SUMMARY}

Based on the measurement results, it can be assumed that compact fluorescent lamps equivalent to 60-Watt incandescent light bulbs exhibit the luminous efficacy within the range of $52-65 \mathrm{~lm} / \mathrm{W}$. This means that they are around five times more energy-efficient than incandescent lamps, whereas the luminous efficacy of the tested halogen light bulb is almost equal to that of a traditional light bulb. This phenomenon is related to the overestimation of the declared luminous flux. The luminous efficacy of the tested LED light sources amounts to an average value of $85 \mathrm{~lm} / \mathrm{W}$. Thus, LEDs exhibit the luminous efficacy that is seven times higher than in traditional lamps. Even so, the luminous efficacy of some LEDs within the test group was found to be comparable with that of fluorescent lamps. One of these LEDs was not a surprise due to its exceptionally low price ( 7 PLN). The other one, however, was trade-marked and had the biggest price tag of all units tested (around 140 PLN), but the technology behind it was unveiled some 5 years ago, which is a large gap if we take into consideration how dynamically these light sources are developing. High energy efficiency of LED light sources allows them to be categorized as A+ energy class, while compact fluorescent lamps fall into the A class, at best.

Overestimation of the luminous efficacy by the manufacturer was uncovered in case of six light sources. In practical terms, the exposed discrepancies between the measured and manufacturer-declared power translates into lower consumption of energy, while the luminous flux remains within the required tolerance.

To sum up, LED sources indeed prove to be the most beneficial replacement for incandescent light bulbs, considering both their operational parameters and their price, which is comparable with the price of compact fluorescent lamps or, in some instances, even lower. The above conclusion was arrived at with the manufacturer's declaration of the light source lifetime considered.

This paper has been prepared on the basis of the results of a research task carried out within the scope of the second stage of the National Programme "Improvement of safety and working conditions" supported in 2014-2016 - within the scope of state services and statutory activity - by the Ministry of Labour and Social Policy.

The Central Institute for Labour Protection - National Research Institute is the Programme's main coordinator.

\section{REFERENCES}

[1] COMMISSION REGULATION (EC) No 244/2009 of 18 March 2009 implementing Directive 2005/32/EC of the European Parliament and of the Council with regard to ecodesign requirements for non-directional household lamps, European Commission, 2009.

[2] COMMISSION REGULATION (EU) No 1194/2012 of 12 December 2012 implementing Directive 2009/125/EC of the European Parliament and of the Council with regard to ecodesign requirements for directional lamps, light emitting diode lamps and related equipment, European Commission, 2012.

[3] COMMISSION DELEGATED REGULATION (EU), No 874/2012 of 12 July 2012 supplementing Directive 2010/30/EU of the European Parliament and of the Council with regard to energy labelling of electrical lamps and luminaires, European Commission, 2012.

[4] Chromaticity difference Specification for Light Sources, CIE Technical Note CIE TN 001, 2014.

[5] Light and lighting. Lighting of work places. Part 1: Indoor work places, European Standard EN 12464-1, 2011.

[6] Photobiological safety of lamps and lamp systems, European Standard EN 62471, 2008.

[7] Self-ballasted lamps for general lighting services. Performance requirement, European Standard EN 60969, 2002.

[8] Self-ballasted LED lamps for general lighting services with supply voltages $>50 \mathrm{~V}$. Performance requirements, European Standard EN 62612, 2013. 
[9] Tungsten filament lamps for domestic and similar general lighting purposes. Performance requirements, European Standard EN 60064, 1995.
[10] Tungsten halogen lamps (non-vehicle). Performance specifications, European Standard EN 60357, 2003.

mgr Andrzej Pawlak

Central Institute for Labour Protection - National Research Institute

Czerniakowska 16, 00-701 Warszawa, POLAND

e-mail:anpaw@ciop.pl

dr Małgorzata Zalesińska

Poznan University of Technology, Faculty of Electrical Engineering

Plac M. Skłodowskiej-Curie 5, 60-965 Poznań, POLAND

e-mail: malgorzata.zalesinska@put.poznan.pl 